\title{
Benthic flow environments affect recruitment of Crassostrea virginica larvae to an intertidal oyster reef
}

\author{
Elizabeth R. Whitman, Matthew A. Reidenbach* \\ Department of Environmental Sciences, University of Virginia, Charlottesville, Virginia 22904, USA
}

\begin{abstract}
Restoration efforts to enhance Crassostrea virginica oyster populations along the Virginia, USA, coastline focus on creating benthic habitat suitable for larval recruitment, survival, and growth. To determine how benthic flow processes affect larval recruitment, velocity and turbulence we collected data over multiple intertidal benthic surfaces including a mud bed, a $C$. virginica oyster reef, and 2 restoration sites comprised of deposited $C$. virginica oyster shell or the relatively larger Busycotypus canaliculatus whelk shell. Mean estimates of the drag coefficient, $C_{\mathrm{D}}$, used as a measure of hydrodynamic roughness over the $C$. virginica reef were found to be 2 times greater than over the restoration sites and 5 times greater than over the mud bed. Enhanced fluid shear increased both peak Reynolds stresses and vertical momentum transport above the reef, but within the interstitial areas between individual oysters, velocities and turbulence were reduced. Larval settlement plates of varying triangular-shaped benthic roughness were used to mimic the natural topographic variability found along oyster reefs. The greatest larval recruitment occurred along interstitial regions between high-roughness topography, where shear stresses, which act to dislodge larvae, were found to be up to 20 times smaller than along exposed surfaces. Greater recruitment was also found on the more hydrodynamically rough whelk shell compared to the oyster shell restoration site. Results suggests that restoration efforts should consider creating 3-dimensional benthic topography similar to established oyster reefs to provide hydrodynamic conditions and settlement surfaces that promote larval recruitment, prevent burial by sediment, and provide refuge from predation.
\end{abstract}

KEY WORDS: Turbulence $\cdot$ Boundary layers $\cdot$ Larvae $\cdot$ Recruitment $\cdot$ Oyster $\cdot$ Crassostrea virginica

Resale or republication not permitted without written consent of the publisher

\section{INTRODUCTION}

The eastern oyster Crassostrea virginica creates 3dimensional, complex reef structure within estuaries and coastal waters that provides habitat for many fish and invertebrate species, promotes estuarine biodiversity (Lenihan \& Peterson 1998), and enhances the value of commercial fisheries (Breitburg et al. 2000). Through active filtration, oysters remove algae and detritus from the water, improving both water quality and water clarity (Newell 1988, Nelson et al. 2004). As a result, dense concentrations of oysters can lo- cally influence processes such as sedimentation (McCormick-Ray 1998) or removal of particulate organic carbon (Dame et al. 1984). Despite the importance of oysters to the local ecosystem, over fishing, disease, and poor management practices have contributed to the loss of $99 \%$ of the historical biomass of C. virginica in the Chesapeake Bay and coastal waters along the east coast of the United States (Rothschild et al. 1994, Kemp et al. 2005). There are now increased efforts to restore oyster reefs (Cerco \& Noel 2007, Schulte et al. 2009) that rely on the creation of highrelief, hard substrate that improves recruitment suc- 
cess of their larvae (Nelson et al. 2004), with the goal of forming a living oyster reef over these created habitats after continued settlement and growth of generations of oysters (Nestlerode et al. 2007).

Larvae preferentially settle on existing oyster reefs because they provide hard, stable substrate that contains topographic variability, thus preventing burial by sediments (Wethey 1986, Butman 1987, Koehl \& Hadfield 2010) and offering protection from predation (Nestlerode et al. 2007). For reefs to develop, oysters must survive a planktonic larval phase that lasts for several weeks (Loosanoff 1965, Coen \& Luckenbach 2000), attach to substrate, and grow from spat to large individuals. Studies have found that the higher the vertical relief of the benthic substrate, the more successful is the recruitment and growth of oysters (Lenihan 1999, Schulte et al. 2009). In addition, oysters within reef interstices were found to grow faster and live longer than oysters found at the reef surface (Bartol et al. 1999), suggesting that factors such as local hydrodynamics and location on the reef with respect to the mean water surface play an important role in oyster survivorship (Breitburg et al. 1995, Bartol \& Mann 1997).

Major challenges for oyster recovery efforts include promoting successful larval transport to and from reef areas, providing accommodating sites for larval settlement, and maintaining environmental conditions suitable for oyster growth and survival (Coen \& Luckenbach 2000, Soniat et al. 2004, Kingsley-Smith et al. 2009). Settlement success for a variety of larval species is dependent upon their ability to quickly land, attach, and undergo metamorphosis before they are washed away by fluid stresses or are transferred to areas where they can be buried by sediment (Turner et al. 1994, Jonsson et al. 2004, Fuchs et al. 2007). Larval transport to the bed is facilitated by turbulent mixing (Hendriks et al. 2006), but larvae must land on the substrate and be exposed to sufficiently low shear stresses over a period of time in order to successfully anchor (Crimaldi et al. 2002). Shear stress acts tangential to their settlement surface and it is this shearing force, in combination with drag and lift forces imposed on larvae by ambient flow, that is capable of dislodging larvae after initial contact with settlement surfaces (Reidenbach et al. 2009, Koehl \& Hadfield 2010). Although previous studies have shown that benthic shear stresses influence the success of larval settlement (Eckman 1990, Mullineaux \& Garland 1993, Soniat et al. 2004), little is known about the actual distributions of shear stresses along oyster beds that larvae are exposed to while settled on these surfaces.
Oyster larvae are also known to exhibit active substrate choice (Turner et al. 1994, Zimmer-Faust \& Tamburri 1994). Like larvae of many other bivalve species, oyster larvae determine proper settlement sites depending upon local hydrodynamics (Fredriksson et al. 2010, Koehl \& Hadfield 2010), and once contacting the bed, if they find their first landing site to be unsuitable, they can release themselves back into the flow and test the next site they come in contact with (Soniat et al. 2004, Fuchs et al. 2007). In studies determining the effect of flow on barnacle larvae, increased settlement was found in regions with high velocity and shear due to increases in arrival rates to these sites (Bushek 1988), but larvae were found to selectively settle to local sites with low shear (Wethey 1986, Mullineaux \& Butman 1991), while deep-water foraminiferal propagules tended to settle in regions of flow separation (Mullineaux \& Butman 1990). Although increased benthic roughness increases both turbulent stress and turbulent mixing within the overlying water column (Butman et al. 1994), low shear is often associated with crevices and narrow protective burrows, or interstitial areas between shell outcroppings. Therefore, due to the high variability in both topography and elevation found on an intertidal oyster reef, flow micro-habitats and local bed shear stresses are expected to exert a strong influence on larval settlement success.

Currently, there are ongoing large-scale efforts to restore oyster populations along the Virginia, USA, coast. One of the primary objectives is to increase suitable oyster habitat by adding hard substrate to the coastal bays in the hope that natural recruitment processes will increase oyster biomass (Coen \& Luckenbach 2000). Based on the heightened focus on oyster restoration and necessity to create suitable benthic habitat for larval recruitment and growth, this study examines how the elevation of the habitat and position within interstices along benthic substrate of different geometric roughness affects the local flow experienced by Crassostrea virginica larva settled on these surfaces. The questions addressed through field research and laboratory experiments are: (1) How do reef elevation and bed roughness affect flow and turbulence in the boundary layer over an intertidal oyster reef and adjacent restoration sites, (2) How does the magnitude and variability of shear stress differ among sites of varying topographies, and (3) How do the varying hydrodynamic conditions surrounding different bed topographies affect rates of larval recruitment? 


\section{MATERIALS AND METHODS}

\section{Study sites}

Field studies were performed along the Virginia, USA coastline to quantify benthic flow dynamics and larval recruitment at 4 intertidal sites of differing benthic roughness and elevation. These sites included a relatively smooth mud bottom, a restoration site composed of deposited single valve Crassostrea virginica oyster shell, a restoration site composed of larger Busycotypus canaliculatus whelk shells, and a mature $C$. virginica reef primarily composed of vertically oriented living oysters. Studies were carried out between May 2009 and November 2010 on an established Crassostrea virginica oyster reef and adjacent restoration sites, located $\sim 1 \mathrm{~km}$ offshore of the Eastern Shore of Virginia, USA within the Virginia Coast Reserve (Fig. 1). The Virginia Coast Reserve is characterized by contiguous marsh, shallow bay, and barrier island systems and is a National Science Foundation-Long Term Ecological Research (NSFLTER) program site. The oyster site is part of a network of numerous healthy patches of oyster reefs surrounding an oyster restoration area operated by The Nature Conservancy. Hydrodynamic and larval recruitment measurements were obtained at 4 sites: an established $C$. virginica reef, a restoration site whose substrate was constructed from deposited $C$. virginica oyster shell, a restoration site constructed from rel-

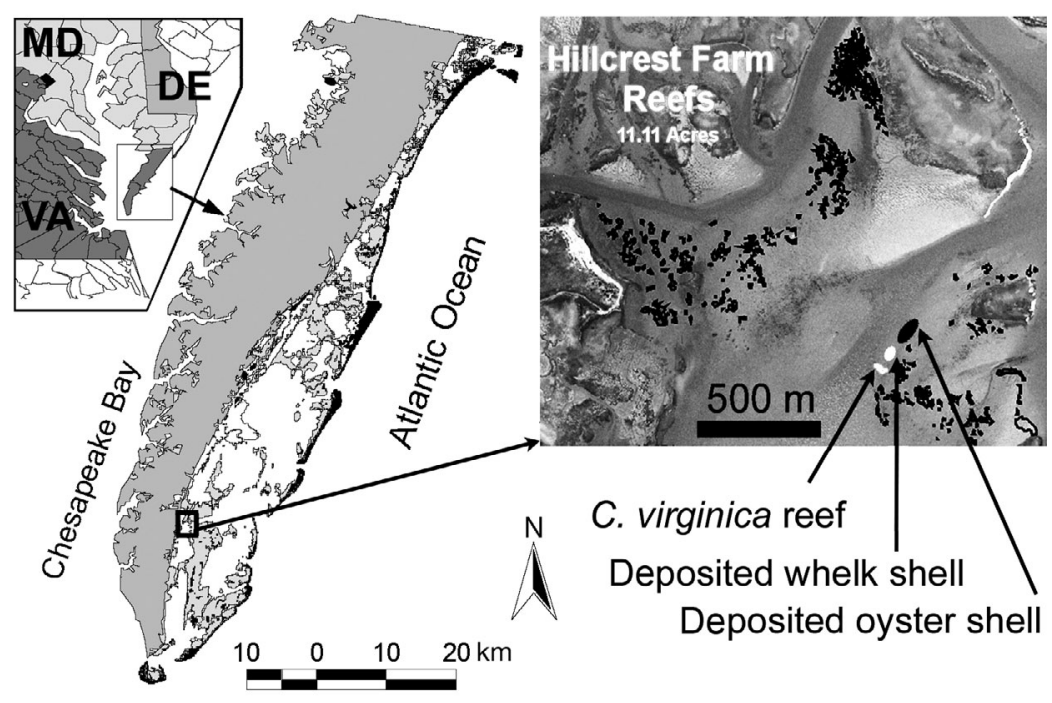

Fig. 1. Delmarva peninsula, Virginia, USA. Aerial pfotograph shows oyster reefs (outlined in black) off the eastern shore of the peninsula and the study sites, including the healthy Crassostrea virginica oyster reef and constructed restoration sites composed of deposited whelk and oyster shell. The mud site is located between the $C$. virginica reef and whelk shell restoration site. DE: Delaware; MD: Maryland; VA: Virginia atively larger Busycotypus canaliculatus whelk shell, and a soft bottom site whose bed was primarily composed of silt and fine-sand sized sediment with $90 \%$ of particles having a diameter $\leq 150 \mu \mathrm{m}$ (Fig. 2). The oyster and whelk shell were dredged from nearby coastal bays and deployed at the restoration sites during the summer of 2008. The total area of the $C$. virginica reef was $270 \mathrm{~m}^{2}$, while the adjacent restoration sites encompassed an area of $3500 \mathrm{~m}^{2}$ for the oyster shell and $240 \mathrm{~m}^{2}$ for the whelk shell. The mud seafloor site, which was located between the healthy and restoration site, encompassed an area of $\sim 1000 \mathrm{~m}^{2}$. All sites were adjacent to one another and located on the bank of a 2-3 m deep tidal channel.

A LaserMark LM800` ${ }^{\circledR}$ laser-based elevation scanner was used to obtain relative elevations of each study site. Mean elevations at the center of each site ( $\pm 1 \mathrm{SD}$ ) relative to the Crassostrea virginica reef were: mud site: $-0.37 \pm 0.10 \mathrm{~m}$, whelk shell: $-0.17 \pm$ $0.11 \mathrm{~m}$, and oyster shell: $-0.01 \pm 0.07 \mathrm{~m}$. The mud and restoration sites were relatively flat, while the healthy C. virginica reef peaked in elevation at its center and decreased in elevation by $\sim 0.75 \mathrm{~m}$ at the reef edge.

\section{Instrumentation}

Four Nortek Inc. Aquadopp ${ }^{\circledR}$ Profilers (AQDPs) were deployed simultaneously at each of the 4 study sites to obtain velocity profiles within the benthic boundary layer. Three of the AQDPs were high-resolution and measured $3-\mathrm{D}$ velocities at a vertical resolution of $0.03 \mathrm{~m}$ at a sampling rate of $1 \mathrm{~Hz}$ between $z=0.1 \mathrm{~m}$ and $0.85 \mathrm{~m}$ above the seafloor at the Crassostrea virginica reef and restoration sites. The fourth AQDP measured velocities at a vertical resolution of $0.1 \mathrm{~m}$ at a sampling rate of $1 \mathrm{~Hz}$ between $z=0.2 \mathrm{~m}$ and $2 \mathrm{~m}$ above the seafloor at the mud site. The AQDPs were secured on frames and deployed on the seafloor in an upward-looking orientation at each site for a $3 \mathrm{~d}$ period. The elevation $z=0 \mathrm{~m}$, was denoted as the datum height at the attachment location of oysters to the substrate on the C. virginica reef, at the base of the shells at the restoration sites, or at the sediment surface at the mud site. During a separate experiment, to determine the effects of reef elevation on 


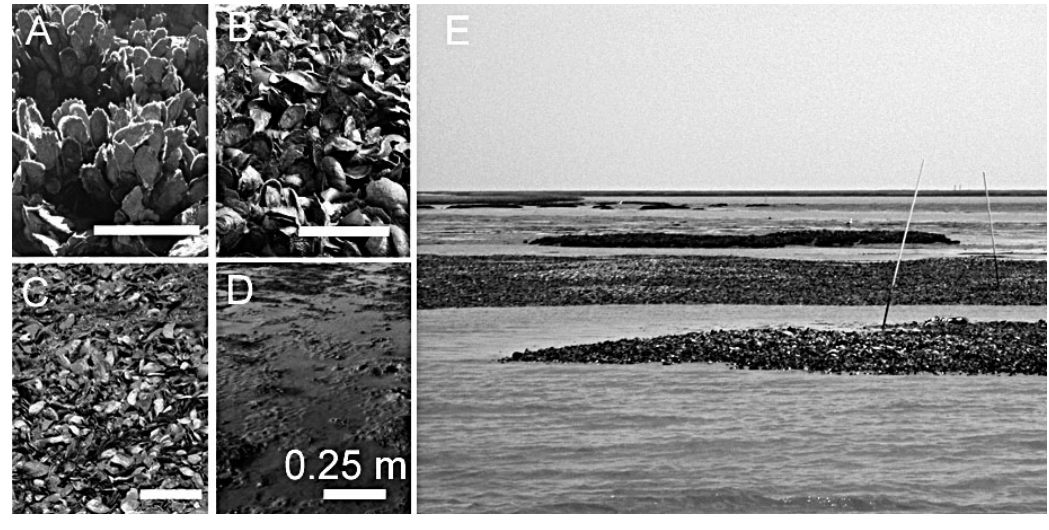

Fig. 2. Study sites: (A) healthy oyster reef, (B) whelk shell restoration site, (C) oyster shell restoration site, and (D) mud site. Scale bar on all images is $0.25 \mathrm{~m}$. (E) Image showing from foreground to background, the oyster shell restoration site, whelk shell restoration site, and healthy oyster reef

distance. Therefore, a boundary layer will grow to a thickness of $z=0.15 \mathrm{~m}$ at a distance $3.0 \mathrm{~m}$ downstream from the edge of a change in roughness. Velocity measurements were conducted at a minimum of $5 \mathrm{~m}$ from the edge of each site to ensure a developed boundary layer within the location of measurements.

Suspended sediment concentrations (SSC) were measured $z=0.15 \mathrm{~m}$ above the seafloor at each site using optical backscatter sensors (OBS, Campbell Scientific OBS3+). SSC data were recorded to the internal memory of the AQDPs. To perform OBS calibrations, sediment samples were collected, dried, and weighed

hydrodynamics, 3 AQDPs were positioned on the $C$. virginica reef: at the top, middle, and base, and spaced $4 \mathrm{~m}$ between instruments along a transect perpendicular to the main axis of the tidal channel. Elevations at each location were $0,-0.35$, and $-0.75 \mathrm{~m}$, relative to the top of the reef.

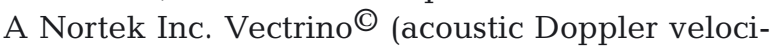
meter) was used to measure fine-scale velocity and turbulence adjacent to and between tightly spaced oysters at the Crassostrea virginica reef, as well as over benthic surfaces at the restoration and mud sites. The Vectrino measurement volume for velocity is located $5 \mathrm{~cm}$ below the transducer head, with a height of $0.4 \mathrm{~cm}$ and diameter of $0.6 \mathrm{~cm}$. The Vectrino was mounted on a stainless steel frame and velocity was measured at $z=0.5,1.0,2.0,3.0,4.0$, 5.0, 7.0, 10.0, and $15.0 \mathrm{~cm}$ above the bed for each vertical profile. In total, 61 velocity profiles at randomly selected locations across the 4 sites were performed. Velocity data were collected at $50 \mathrm{~Hz}$ for 10000 samples at each elevation. The Vectrino had no internal memory storage; therefore, the instrument was cabled to a computer stationed on a moored boat that was positioned $15 \mathrm{~m}$ downstream from the sampling location to ensure no interference with the flow. The oyster shell restoration site covered an area of $3500 \mathrm{~m}^{2}$, more than 10 times the area of the $C$. virginica reef $\left(270 \mathrm{~m}^{2}\right)$, or the whelk shell restoration site $\left(240 \mathrm{~m}^{2}\right)$. Larger areas will have a greater overall effect on flow structure, although due to the high roughness of the reef, boundary layers are expected to quickly form. Antonia \& Luxton (1971) found that vertical growth of a boundary layer in response to a change in roughness occurs at $\sim 1 / 20$ th the horizontal downstream from sediment collected adjacent to the healthy oyster reef. Dried sediment was mixed in known quantities into 601 filtered seawater and a linear regression was formed between backscatter intensity from the OBS and suspended sediment concentration. Three OBSs were independently calibrated, each having a linear correlation between backscatter intensity and sediment concentration of $\mathrm{R}^{2}>0.99$.

\section{Data analysis}

Velocities were collected with the AQDPs at each site in East-North-Up (ENU) coordinates, and the root mean square horizontal velocity, $U$, was calculated as:

$$
U=\left(U_{\mathrm{e}}^{2}+U_{\mathrm{n}}^{2}\right)^{0.5}
$$

where $U_{\mathrm{e}}$ and $U_{\mathrm{n}}$ is the velocity to the east and north direction, respectively. Bed shear stress, $\tau=\rho u^{2}$ (where $u$ * is the shear velocity and $\rho$ is the density of the fluid), is a measure of the frictional interaction between the flow and the seafloor. To quantify $\tau$ and $u *$, mean flow and turbulence measurements were measured within the water column and used to infer stresses imposed at the bed. The shear velocity, $u_{*}$, was calculated from profiles of mean velocity using the 'law of the wall' equation (e.g. Schlichting \& Gersten 2000):

$$
U(z)=\frac{u *}{\kappa} \ln \left(\frac{z-d}{z_{\mathrm{o}}}\right)
$$

where $\kappa=0.41, z$ is the height above the bed, $z_{0}$ is the roughness length-scale, and $d$ is the roughness height, which is a vertical offset to account for 
changes in elevation of the bed relative to datum. Since the flow in the benthic boundary layer is assumed to be turbulent and fully rough, Eq. (2) can be used to appropriately describe the velocity profile (Cheng et al. 1999). Estimates of $u \cdot$ and $z_{\mathrm{o}}$ were obtained by a linear regression of the velocity magnitude $(U)$ to $\ln (z)$ using 10 min averaged velocity profiles. This time period was chosen because in statistical tests $10 \mathrm{~min}$ often emerges as the best balance between obtaining convergence of the mean statistics, while minimizing velocity drift due to changes in tidal flow conditions (Gross \& Nowell 1983). Ten velocity measurements were used in the regression, and only those with a correlation coefficient $\mathrm{R}^{2}=0.95$ or greater were accepted, giving a mean uncertainty (95\% CI) of $\pm 19 \% u$. and $\pm 35 \%$ $z_{\mathrm{o}}$ (Lueck \& Lu 1997). Velocity profiles were only performed when wave activity was minimal (significant wave heights $<10 \mathrm{~cm}$ ) and profiles that were eliminated due to low $\mathrm{R}^{2}$ were typically taken during times of large flow accelerations and decelerations caused by tidal variability.

\section{Larval settlement plates}

Larval settlement plates composed of triangularshaped slate tiles of varying height:spacing ratios were used to test the effects of benthic roughness on recruitment of oyster larvae (Fig. 3). Slate tiles were cemented into trays measuring $35 \times 80 \mathrm{~cm}$ and arranged using a height:spacing ratio of 1:1 (height $=$ spacing $=10 \mathrm{~cm}), 2: 1$ (height $=10 \mathrm{~cm}$, spacing = $5 \mathrm{~cm}$ ), or a flat orientation with a height:spacing ratio of 0 . The varying height:spacing ratios of settlement plates were used to span the possible roughness length scales typically found at the 4 study sites. Five replicates of each geometry were made and all structures were deployed on the oyster shell restoration site for a 5 mo period between July and December 2010. The typical spawning period for Crassostrea virginica is June through September (Kennedy \& Krantz 1982). At the end of the 5 mo deployment, juvenile oyster counts were performed, and separated into size classes determined by their shell length.

\section{Laboratory flume and instrumentation}

Laboratory experiments were conducted within an open channel recirculating water flume to quantify turbulent bed shear stresses that would be encoun-
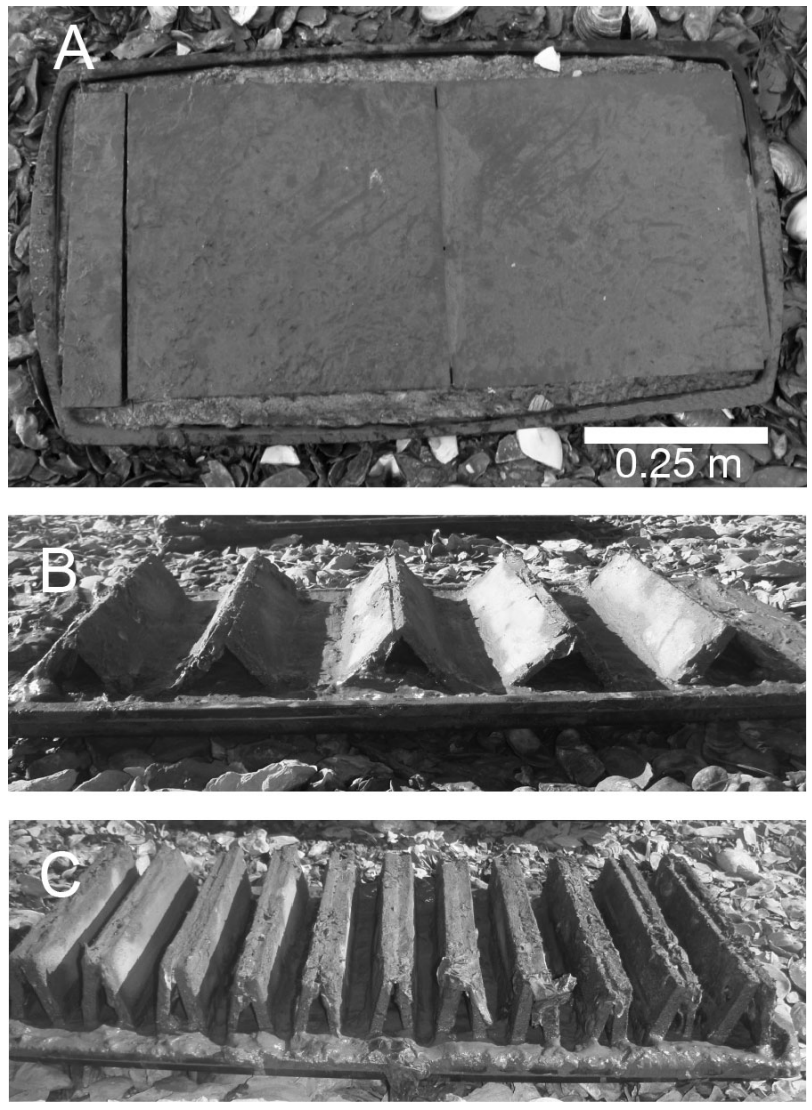

Fig. 3. Slate larval settlement plates showing 3 different geometries, (A) height:spacing $=0$, (B) height:spacing $=1$, and $(C)$ height:spacing $=2$. Images were taken 2 mo after deployment during low tide

tered by larvae settled at different positions on the settlement plates. The flume, based on schematics by Tamburri et al. (1996), was constructed from Lexan ${ }^{\circledR}$ thermoplastic, and had overall channel dimensions of $0.2 \mathrm{~m}$ wide by $0.3 \mathrm{~m}$ high, with semicircular ends of radius $0.4 \mathrm{~m}$ connected with 2 straight sections $1 \mathrm{~m}$ long. Two additional sheets of Lexan ${ }^{\circledR}$ were placed within each curved section of the flume parallel to the walls to minimize secondary flow created around the curves. The test section wall was fitted with a $1 \mathrm{~m}$ long glass insert to improve image clarity. Flow was driven by a variable speed motor attached to 10 vertically rotating vinyl disks $(30 \mathrm{~cm}$ diameter long-play records), spaced $2 \mathrm{~cm}$ apart. Benthic structures were constructed from Lexan ${ }^{\circledR}$ cut to the width of the flume $(20 \mathrm{~cm})$ and sized using height:spacing ratios of $0,0.5,1.0,1.5$ and 2.0, to span the range of roughness of the settlement plates used in the field studies. Water depth was held constant at $0.25 \mathrm{~m}$ for all experiments, with a minimum depth over the top of the benthic structures of $0.15 \mathrm{~m}$. 
Velocity and turbulence measurements were obtained using a particle image velocimetry (PIV) technique. The PIV system consisted of a laser (Laserglow Technologies ${ }^{\circledR} 300 \mathrm{~mW}, 532 \mathrm{~nm}$ ) and optics (Melles Griot ${ }^{\circledR} 20^{0}$ convex lens) to create a laser light sheet $\sim 0.2 \mathrm{~cm}$ thick by $20 \mathrm{~cm}$ wide. This light illuminated neutrally buoyant particles released into the flow (11 micron silver coated hollow glass spheres, Potter Industries ${ }^{\circledR}$ ), and using a digital camera (Sony High Definition HC7) particles were imaged at a framing rate of $30 \mathrm{~Hz}$. Videos were separated into successive image pairs and processed using a hybrid digital PIV technique (Cowen \& Monismith 1997). This technique calculates the most probable displacements of particles in successive pairs of frames using cross correlation analysis. The final output from the software produced horizontal and vertical velocity estimates for every 8 by 8 pixel sub-window, giving 240 by 135 velocity measurements per image pair. Accuracy of the PIV measurements was estimated using a tow-tank facility (described in Reidenbach et al. 2008) and found to be $\pm 6 \%$ of measured velocity. Mean velocities of 5, 10, 15, and $20 \mathrm{~cm} \mathrm{~s}^{-1}$ were tested for each of the 5 different height:spacing bed ratios. The total PIV image area within the flume was $16 \mathrm{~cm}$ by $9 \mathrm{~cm}$, giving a spatial resolution of velocity vectors of $0.07 \mathrm{~cm}$.

Crassostrea virginica larva adhere to the substratum with a thin, flattened foot, and its bulbous shellcovered body has a typical diameter $d \approx 300 \mu \mathrm{m}$ (Thompson et al. 1996). For the purpose of calculating water velocities and bed shear stress affecting a larva attached to a surface, the larva was approximated as a sphere with a diameter of $300 \mu \mathrm{m}$. Velocities $(u)$ in the streamwise direction were interpolated to a distance $300 \mu \mathrm{m}$ from the surface assuming a linear distribution in velocity between the surface (where $u=$ $0 \mathrm{~cm} \mathrm{~s}^{-1}$ due to the no slip boundary condition) and the first velocity measurement at $700 \mu \mathrm{m}$ from the surface. This is a reasonable assumption because the thickness of the viscous sublayer $\left(\delta_{\mathrm{v}}=10 \mathrm{v} / u_{*}\right.$, where $v=1 \times 10^{-6} \mathrm{~m}^{2} \mathrm{~s}^{-1}$ is the kinematic viscosity of seawater at $25^{\circ} \mathrm{C}$ ) was estimated to be 500 to $1000 \mu \mathrm{m}$ over the range of flows tested. Within and slightly above the viscous sublayer, the velocity profile is expected to be linear and the local bed shear stress can be computed at the point of larval attachment as $\tau_{\mathrm{o}}=\rho v(\partial u / \partial z)$. Here, $\tau_{\mathrm{o}}$ is used to describe the local bed shear stress computed at the point of larval attachment to differentiate it from the area-averaged bed shear stress, $\tau$, computed from estimates using Eq. (2). For each flow and bed geometry combination, 5400 images spanning $180 \mathrm{~s}$ were recorded and ana- lyzed. Nowell \& Jumars (1987) suggest that the width-to-depth ratio in the measurement region of interest be greater than 5 to reduce flow effects from the sidewalls. Velocity measurements at $700 \mu \mathrm{m}$ above the bed have a minimum width-to-depth ratio of 280, ensuring that our stress measurements are not appreciably affected by the sidewalls.

\section{RESULTS}

\section{Effects of bed topography on flow and hydrodynamic drag}

Depth-averaged mean velocities, $U_{\mathrm{d}}$, were significantly greater at the whelk shell restoration and mud site than those measured at the oyster shell restoration or Crassostrea virginica reef sites (Table 1). The mud site and whelk shell restoration sites were both lower in elevation than the $C$. virginica reef or oyster restoration site, and, therefore, were submerged over a greater time period during each tidal cycle, exposing these sites to larger ebb and flood conditions (Fig. 4). At all sites, a trend of increasing $u_{*}$ with velocity occurred, with $u *$ near $0 \mathrm{~cm} \mathrm{~s}^{-1}$ during slack tides. Using estimates of $u *$, the area-averaged bed shear stress, computed as $\tau=\rho u^{2}$, ranged between $\tau=0 \mathrm{~Pa}$ at slack tide to maximum values of $\tau=4.0 \mathrm{~Pa}$ at the $C$. virginica reef, $\tau=1.2 \mathrm{~Pa}$ at the restoration sites, and $\tau=0.9 \mathrm{~Pa}$ at the mud site.

To quantify how shear stress varies with mean flow, a drag coefficient $\left(C_{\mathrm{D}}\right)$ was calculated (Schlichting \& Gersten 2000) as:

$$
C_{\mathrm{D}} \equiv \frac{u^{2}}{U_{\mathrm{o}}^{2}}
$$

where $U_{\mathrm{o}}$ is the horizontally averaged velocity at an elevation of $z=0.4 \mathrm{~m} . C_{\mathrm{D}}$ ranged between 0.004 and 0.019 and followed expectations of greatest drag at the Crassostrea virginica reef and lowest drag at the mud site. $C_{D}$ at the $C$. virginica reef was $\sim 6$ times greater than the canonical value of $C_{\mathrm{D}}=0.003$ often reported for flows over muddy sites (i.e. Gross \& Nowell 1983), but comparable to those found for flows over coral reefs of $C_{\mathrm{D}}=0.01$ to 0.015 (Reidenbach et al. 2006).

\section{Effects of reef elevation on flow and hydrodynamic drag}

Depth averaged velocities, $U_{\mathrm{d}}$, at the top, middle $(-0.35 \mathrm{~m}$ below the top), and base $(-0.75 \mathrm{~m}$ below the 
Table 1. Mean velocities and drag parameters calculated for the study sites. $U_{\mathrm{d}}$ is the depth averaged velocity measured between elevation $z=0$ and $0.4 \mathrm{~m}$, and elevations are relative to the top of the Crassostrea virginica reef. The shear velocity, $u *$, and roughness length-scale, $z_{0}$, were computed from Eq. (2), while the coefficient of drag, $C_{\mathrm{D}}$, was computed using Eq. (3)

\begin{tabular}{|lccccc|}
\hline Site & $\begin{array}{c}\text { Elevation } \\
(\mathrm{cm})\end{array}$ & $\begin{array}{c}U_{\mathrm{d}} \\
\left(\mathrm{cm} \mathrm{s}^{-1}\right)\end{array}$ & $\begin{array}{c}u \cdot \\
\left(\mathrm{cm} \mathrm{s}^{-1}\right)\end{array}$ & $\begin{array}{c}z_{\mathrm{o}} \\
(\mathrm{cm})\end{array}$ & $C_{\mathrm{D}}$ \\
\hline C. virginica reef & 0 & 11.3 & 2.4 & 1.7 & $0.019 \pm 0.004$ \\
Whelk shell restoration & -17 & 16.3 & 1.9 & 1.5 & $0.011 \pm 0.003$ \\
Oyster shell restoration & -1 & 12.1 & 0.9 & 0.4 & $0.009 \pm 0.001$ \\
Mud & -37 & 17.9 & 1.1 & 0.3 & $0.004 \pm 0.001$ \\
\hline
\end{tabular}

mean $C_{D}=0.006 \pm 0.002$ at the reef base, $C_{\mathrm{D}}=0.008 \pm 0.003$ at mid-reef, and $C_{\mathrm{D}}=0.017 \pm 0.006$ at the reef top.

\section{Suspended sediment concentrations}

During the 3 d sampling period, suspended sediment concentrations were measured along the top of the Crassostrea virginica reef where $\mathrm{SSC}=$ $39.1 \mathrm{mg} \mathrm{l}^{-1}$, while at mid-reef, SSC was $65.0 \mathrm{mg} \mathrm{l}^{-1}$. The top of the reef was

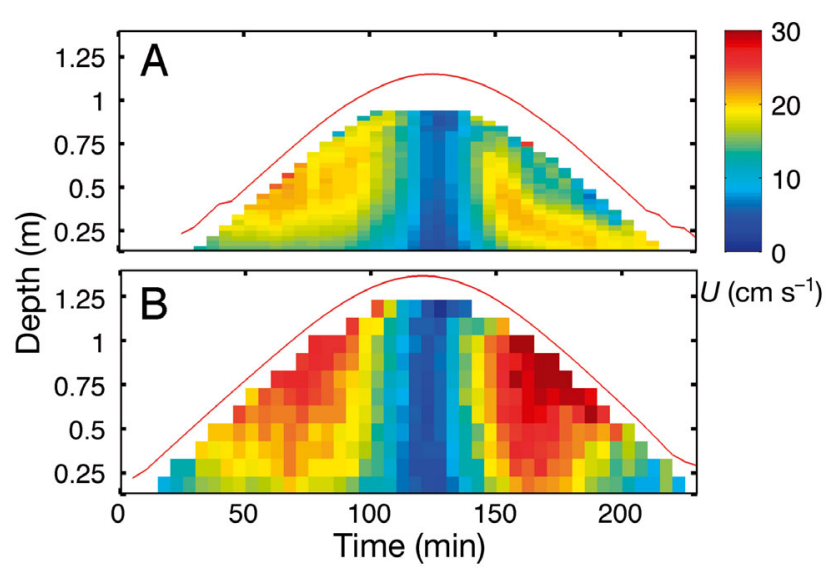

Fig. 4. Profiles of mean horizontal velocity $U$ at the (A) whelk shell restoration site and (B) mud site, averaged over 6 tidal cycles. During each tidal cycle, all sites were submerged for $\sim 4 \mathrm{~h}$. The solid red line denotes water surface elevation. Loss of data near the surface is due to poor signal-to-noise ratios of velocity measurements

top) of the Crassostrea virginica reef were 11.0, 13.1, and $20.8 \mathrm{~cm} \mathrm{~s}^{-1}$, respectively (Table 2). Mean $u *$ and $z_{0}$ measured at the 3 elevations along the reef indicates that $z_{\mathrm{o}}$ increased with increasing reef elevation, but $u$ * was greatest at the reef base. Although relatively greater $u$ * values were found at the reef base, $u$ * estimates increased with increasing velocity; therefore, $C_{D}$ increased with reef elevation, where

Table 2. Mean velocities and drag parameters calculated for the 3 elevations along the Crassostrea virginica reef. $U_{\mathrm{d}}$ is the depth averaged velocity measured between $z=0 \mathrm{~m}$ and $0.4 \mathrm{~m}$. Elevations are relative to the top of the reef. Other abbreviations as in Table 1

\begin{tabular}{|lccccc|}
\hline $\begin{array}{l}\text { Location on } \\
\text { C. virginica reef }\end{array}$ & $\begin{array}{c}\text { Elevation } \\
(\mathrm{cm})\end{array}$ & $\begin{array}{c}U_{\mathrm{d}} \\
\left(\mathrm{cm} \mathrm{s}^{-1}\right)\end{array}$ & $\begin{array}{c}u * \\
\left(\mathrm{~cm} \mathrm{~s}^{-1}\right)\end{array}$ & $\begin{array}{c}z_{\mathrm{o}} \\
(\mathrm{cm})\end{array}$ & $C_{\mathrm{D}}$ \\
\hline top & 0 & 11.0 & 2.1 & 2.1 & $0.017 \pm 0.006$ \\
middle & -35 & 13.1 & 0.9 & 1.5 & $0.008 \pm 0.003$ \\
base & -75 & 20.8 & 1.9 & 0.6 & $0.006 \pm 0.002$ \\
\hline
\end{tabular}

predominantly hard substrate composed of vertically growing live oysters with no notable sediment covered areas, while at mid-reef, $35 \mathrm{~cm}$ lower in elevation, the bed was a mix of live oysters, oyster shell, and regions covered with sediment. During a separate $3 \mathrm{~d}$ sampling time period, measurements were performed to simultaneously compare SSC at the C. virginica reef top to the 2 restoration sites. Mean SSC was $53.2 \mathrm{mg} \mathrm{l}^{-1}$ at the $C$. virginica reef, $62.7 \mathrm{mg}$ $\mathrm{l}^{-1}$ at the whelk shell site, and $64.3 \mathrm{mg} \mathrm{l}^{-1}$ at the oyster shell site. At all locations, SSC was lowest during slack tide and greatest during time periods of intense water velocities $\left(U_{\mathrm{d}}>15 \mathrm{~cm} \mathrm{~s}^{-1}\right)$, which occurred during flooding and ebbing tides.

\section{Small-scale hydrodynamics}

A Nortek Vectrino ${ }^{\circledR}$ was used to measure fine-scale velocities and turbulent stresses adjacent to benthic surfaces. Representative velocity profiles at each site are plotted in Fig. 5 along with turbulent Reynolds stresses, computed as the time average of the horizontal, $u^{\prime}$, and vertical, $w^{\prime}$, velocity fluctuations:

$$
\text { Reynolds stress }=\overline{u^{\prime} W^{\prime}}
$$

Reynolds stresses at the Crassostrea virginica reef were greatest at an elevation of $z=6 \mathrm{~cm}$, approximately equivalent to the height of the top of the vertically oriented oysters and corresponded to a region where an inflection point occurred in the mean velocity profile (Fig. 5A,B). Above this elevation, velocities followed a logarithmic profile. The combination of a peak in the Reynolds stress profile and inflection in the velocity profile at the top of the oysters is indicative of the formation of a shear layer (Lacey \& Roy 2008). Within the oyster bed, between 

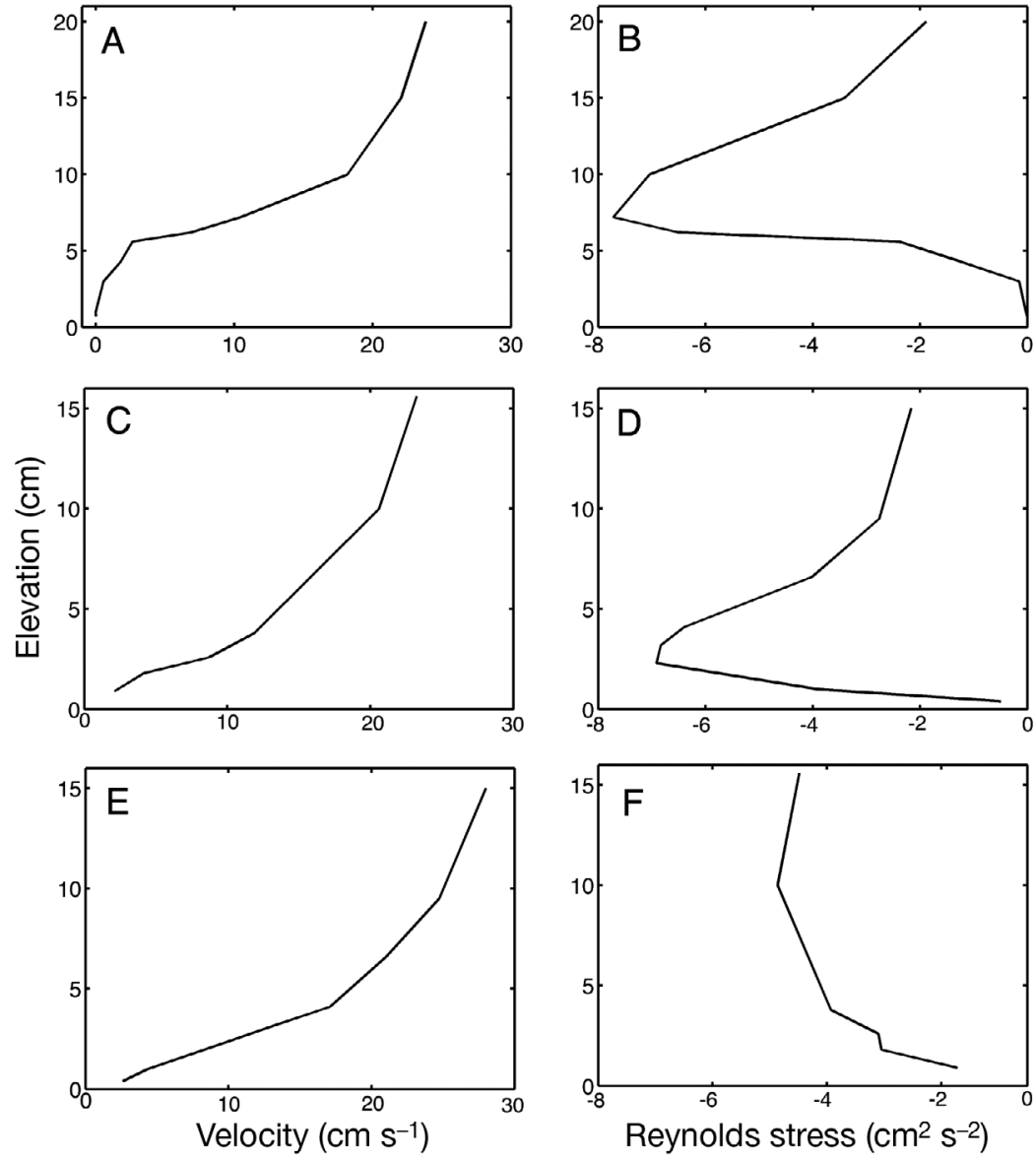

Fig. 5. Profiles of (A) mean velocity $U$ and (B) Reynolds stress $\left(\overline{u^{\prime} w^{\prime}}\right)$ at the Crassostrea virginica reef, (C) mean velocity and (D) Reynolds stress at the oyster restoration site, and (E) mean velocity and (F) Reynolds stress at the mud site

the vertically oriented oyster shells, both velocities and Reynolds stresses decreased and approached values near zero at the base of the oysters where they attach to the solid reef substrate. At the oyster shell (Fig. 5C,D) and whelk shell restoration site (not shown), Reynolds stresses were greatest $2-3 \mathrm{~cm}$ above the bed, similar to the height of local shell roughness elements. However, neither velocities nor Reynolds stresses decayed to zero at the lowest sampling location, at $z=0.5 \mathrm{~cm}$ above the seafloor. At the mud site (Fig. 5E,F), a logarithmic distribution in velocity occurred throughout the entire profile, with no inflection in the mean velocity profile, suggesting that a shear layer did not form over this smoother seafloor region. Results suggest that enhanced benthic roughness creates the formation of shear layers, which locally enhance regions of high turbulence above the roughness elements, but reduce the magnitude of turbulence and velocities within interstitial spaces between roughness elements.

\section{Instantaneous turbulent motions affecting larval transport and recruitment}

Quadrant analysis describes how instantaneous turbulent fluctuations in velocity contribute to momentum distribution throughout the bottom boundary layer (Lu \& Willmarth 1973). Quadrant analysis was performed by separating $u^{\prime}$ and $w^{\prime}$ velocity fluctuations collected at $50 \mathrm{~Hz}$ into 4 quadrants based on the sign of their instantaneous values. Contours of the turbulent probability distribution function (pdf) are shown in Fig. 6A for turbulent motions $z=15 \mathrm{~cm}$ above the Crassostrea virginica reef, and correspond to the time-averaged profiles shown in Fig. 5: in Quadrant 1 (Q1), $u^{\prime}>$ $0, w^{\prime}>0$; in Q2, $u^{\prime}<0, w^{\prime}>0$ (a turbulent ejection); in Q3, $u^{\prime}<0, w^{\prime}<0$; and in Q4, $u^{\prime}>0, w^{\prime}<0$ (a turbulent sweep). Sweeping events, as indicated by pdf values in Q4, transport high momentum fluid downward towards the reef. Conversely, pdf values in Q2 indicate ejection of low momentum fluid vertically upwards away from the reef. The total contribution to the Reynolds Stress within each quadrant can be found by summing the $u^{\prime} w^{\prime}$ contributions: Q1 $(8 \%)$, Q2 $(33 \%)$, Q3 $(7 \%)$, and Q4 (51\%). This indicates that the combined Q2 and Q4 contributions accounted for $\sim 84 \%$ of the total Reynolds stress, which is similar to results found by other studies of flow over high roughness topography (Bennet \& Best 1996, Lacey \& Roy 2008). More specifically, Q4 events dominated overall, indicating that the turbulent sweeps of vortices dominated the fractional contribution, transporting high momentum eddies of fluid towards the reef. These ejection or sweep phenomena also result in intermittent flushing of low momentum 'dead water' that accumulates between roughness elements (Grass 1971). For the oyster shell restoration site (Fig. 6B), there was a more even balance of ejection/ sweep events, with contributions within the quadrants of: Q1 (16\%), Q2 (35\%), Q3 (14\%), and Q4 (35\%). At the mud site, ejections dominated with $46 \%$ of the turbulent motions within Q2, suggesting that higher roughness imparts a greater proportion of turbulent fluctuations that create downward sweeps of high momentum fluid towards the seafloor. 

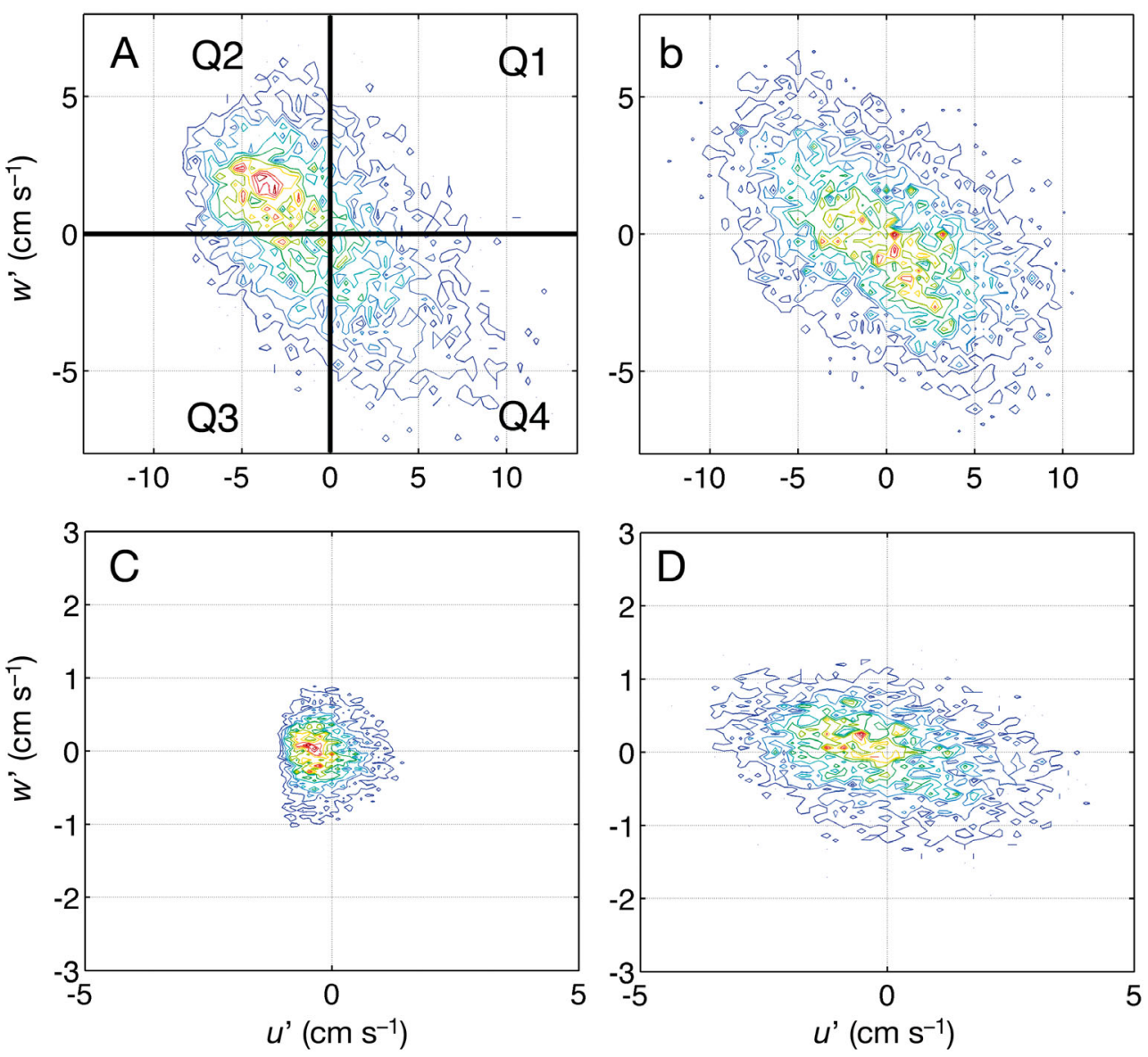

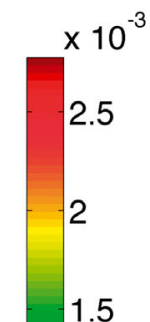

1

0.5

Fig. 6. Quadrant analysis of the probability distribution functions (pdfs) of horizontal $\left(u^{\prime}\right)$ and vertical ( $\left.w^{\prime}\right)$ velocity fluctuations at an elevation $(z)=15 \mathrm{~cm}$ above the (A) Crassostrea virginica reef and (B) oyster shell restoration site, and at $z=0.5 \mathrm{~cm}$ above the (C) C. virginica reef and (D) oyster shell restoration site. Values within Quadrant 2 (Q2), $u^{\prime}<0, w^{\prime}>0$, are turbulent ejections that transport low momentum fluid away from the seafloor, while values in Quadrant 4 (Q4), $u^{\prime}>0, w^{\prime}<0$, are turbulent sweeps that transport high momentum fluid towards the seafloor

At $z=0.5 \mathrm{~cm}$ above the Crassostrea virginica reef, the magnitude of instantaneous turbulent stresses are drastically reduced and there is no statistical difference in the contributions to the Reynolds stress from the various quadrants (Fig. 6C). This occurs because velocities within the interstices between densely packed, vertically oriented oysters are low. Time averaged Reynolds stress is near zero $\left(\overline{u^{\prime} W^{\prime}}=0\right)$ with peak instantaneous stresses $\left(u^{\prime} w^{\prime}\right)$ and peak fluid velocities $\sim 50$ times lower than at $z$ $=15 \mathrm{~cm}$ above the bed. For the oyster shell restoration site, there is still substantial flow and Reynolds stress adjacent to the bed, with equal contributions in Q2 and Q4 (Fig. 6D), suggesting both ejection and sweep motions can affect larva actively exploring the benthic surface. Peak instantaneous stresses are $\sim 10$ times greater at an elevation of $z=0.5 \mathrm{~cm}$ at the restoration site compared to the $C$. virginica reef.

\section{Larval recruitment on restoration sites and settlement plates}

Oyster densities at the 4 sites were estimated for juvenile oysters with shell lengths between 2 and $75 \mathrm{~mm}$ using counts within randomly placed $0.0625 \mathrm{~m}^{2}$ quadrats. Counts were performed during the summer of 2009, 1 yr after creation of the oyster shell and whelk shell restoration sites. Average juvenile densities $( \pm 1 \mathrm{SD})$ were $7500 \pm 3800$ oysters $\mathrm{m}^{-2}$ on the Crassostrea virginica reef, $4100 \pm 1200$ oysters $\mathrm{m}^{-2}$ on the whelk shell, and $420 \pm 120$ oysters $\mathrm{m}^{-2}$ on the oyster shell restoration site. Average shell length of juvenile oysters measured at each site were not statistically different from one another, with $22 \pm 19 \mathrm{~mm}, 23$ $\pm 21 \mathrm{~mm}$, and $30 \pm 15 \mathrm{~mm}$ at the $C$. virginica reef, whelk shell, and oyster shell restoration sites, respectively. No recruitment of juvenile oysters was found at the mud site. 
Counts of juvenile oysters with shell lengths between 2 and $75 \mathrm{~mm}$ on the settlement plates were conducted to determine recruitment success after the 5 mo deployment period. Structures with narrow triangular-spacing (height:spacing $=2$ ) had significantly more recruitment than structures with wide spacing (height:spacing $=1$, ANOVA 2-factor with replication, $\mathrm{p}<0.05$, Fig. 7), and a significant increase in recruitment density was found among the top half of the triangular structure (peaks) compared to the bottom half of the structure (valleys), (ANOVA 2 -factor with replication, $\mathrm{p}<0.05)$. No recruitment was found on the flat settlement plates (height: spacing $=0$ ), which were covered by sediment at the end of the 5 mo deployment period. Total densities were $260 \pm 55$ oysters $\mathrm{m}^{-2}$ on the narrow spaced and $160 \pm 45$ oysters $\mathrm{m}^{-2}$ on the wide spaced triangular roughness.

The distribution of oyster shell lengths of individuals on the settlement plates were quantified for the narrow and wide-spaced triangular structures (Fig. 8) and, although abundances were greater on the narrow spaced structures, there was no statistical difference in the distribution of size classes between the narrow and wide spaced structures. The majority of oysters that settled on the plates grew to a size of 10 to $19 \mathrm{~mm}$.

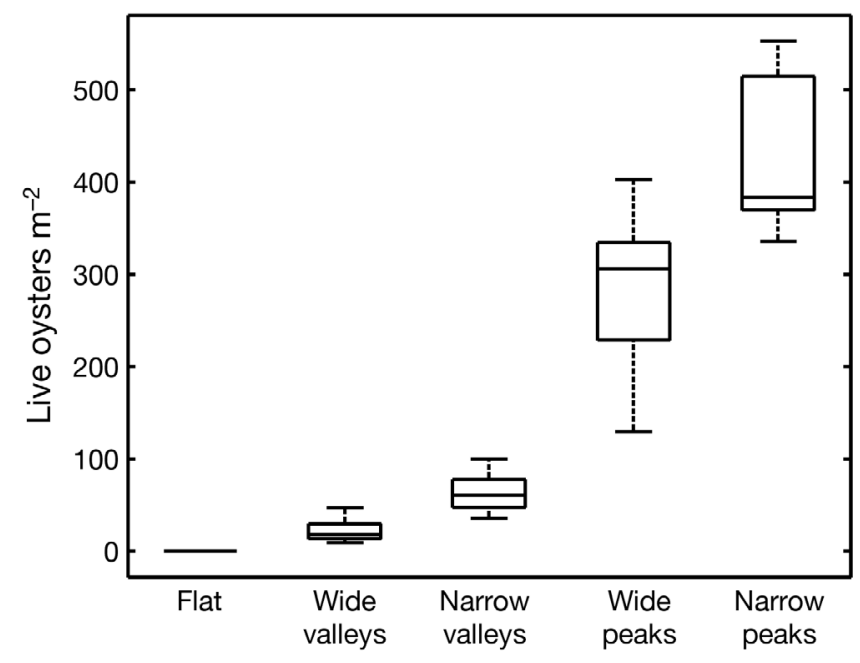

Fig. 7. Recruitment of juvenile oysters on settlement plates. The peaks of structures (upper half of roughness elements) along narrow spaced roughness (height:roughness $=2$ ) had the greatest recruitment and the valleys of structures (lower half of roughness elements) with wide spaced roughness (height:spacing $=1$ ) had the least recruitment. No recruitment was found on the flat settlement plates. Horizontal line within the box indicates median, while the lower and upper edges of the box represent the 25th and 75th percentiles, respectively. Vertical lines extending from the box indicate the minimum and maximum measured oysters $\mathrm{m}^{-2}$

\section{Small-scale hydrodynamics affecting larval settlement}

Velocities computed from PIV within the laboratory flume were used to compute water velocities and bed shear stresses that would be encountered by Crassostrea virginica larvae settled on surfaces located at the mid-point between the peak and valley of the roughness elements. PIV images for a benthic roughness with height:spacing ratio $=2$ is shown in Fig. 9 and indicates a typical logarithmic velocity profile that forms above roughness elements, a strong velocity gradient generated along the peaks of roughness, and 2 counter-rotating vortices with substantially reduced velocity within the interstices between roughness elements. Although 2 counter-rotating vortices were not formed for all height:spacing ratios tested, all structures showed substantially reduced velocities within interstices between roughness elements compared to the flow formed above. $\tau_{\mathrm{o}}$ was calculated for structures with height:spacing ratios $=0,0.5,1.0,1.5$, and 2.0, and show decreasing magnitudes with increased height:spacing roughness ratios (Fig. 10). These results indicate that along flat surfaces, bed shear stresses are between 3 and 20 times larger than along any surface with height:spacing $>0$. Although no measurements have been made for attachment strengths of oyster larvae, bed shear stresses required to dislodge newly settled barnacle cyprids, Balanus amphitrite, have been measured and ranged from 0.2 to $8.7 \mathrm{~Pa}$ (calculated from boundary shear velocities reported by Eckman et al. 1990). This sug-

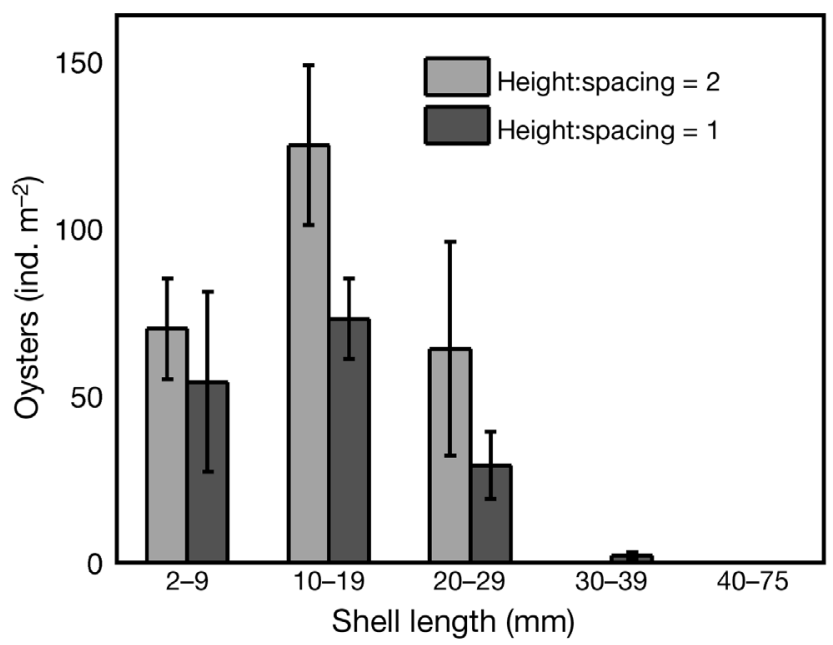

Fig. 8. Size distribution (shell length \pm SD) of juvenile oysters on settlement plates settled on the narrow (height: spacing $=2$ ) and wide (height:spacing = 1) spaced roughness. Size class was determined by the shell length of each individual 

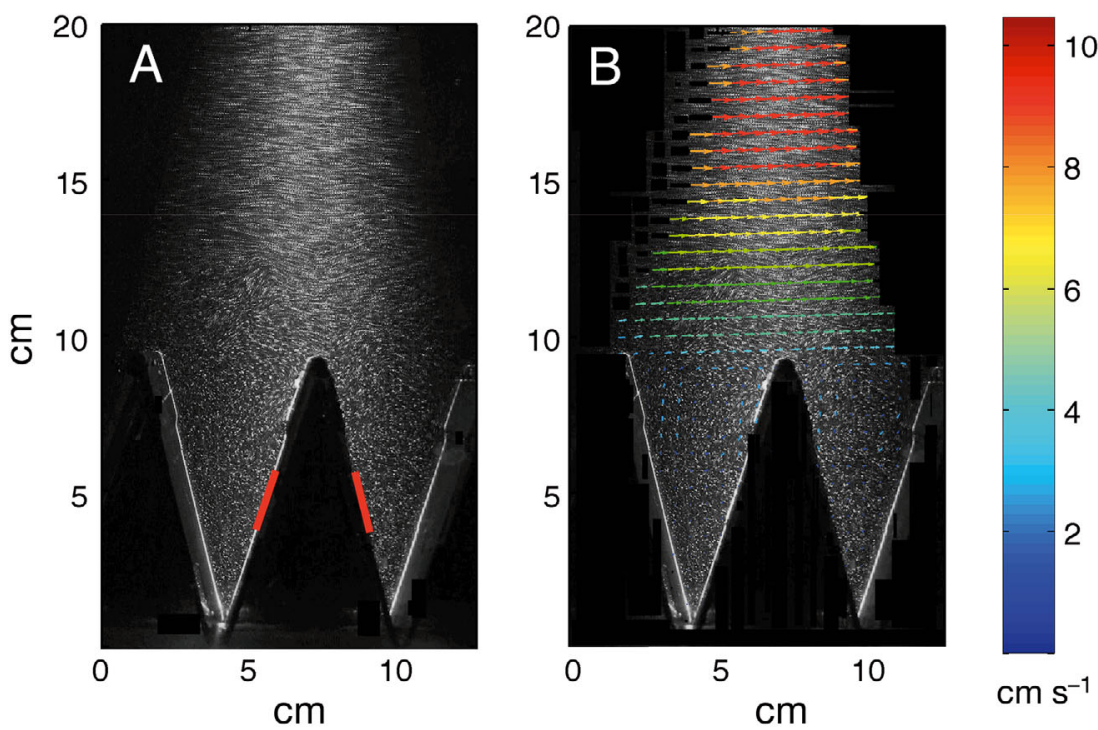

Fig. 9. Particle image velocimetry images taken within the laboratory flume with a $10 \mathrm{~cm} \mathrm{~s}^{-1}$ mean flow over height:spacing $=2$ roughness. (A) Raw image of particles illuminated by laser sheet. The region along the benthic surface where drag and lift forces, as well as bed shear stresses were measured is outlined in red. (B) Color-coded vectors of mean velocity $\left(\mathrm{cm} \mathrm{s}^{-1}\right)$ created by averaging 1000 successive image pairs $(30 \mathrm{~Hz}$ framing rate) of particle motion. Note substantial reduction in velocity within interstitial regions below the peaks of roughness

gests substantial increases in successful attachment and recruitment to surfaces is likely for oyster larvae when landing on interstitial surfaces sheltered from high velocity and bed shear.

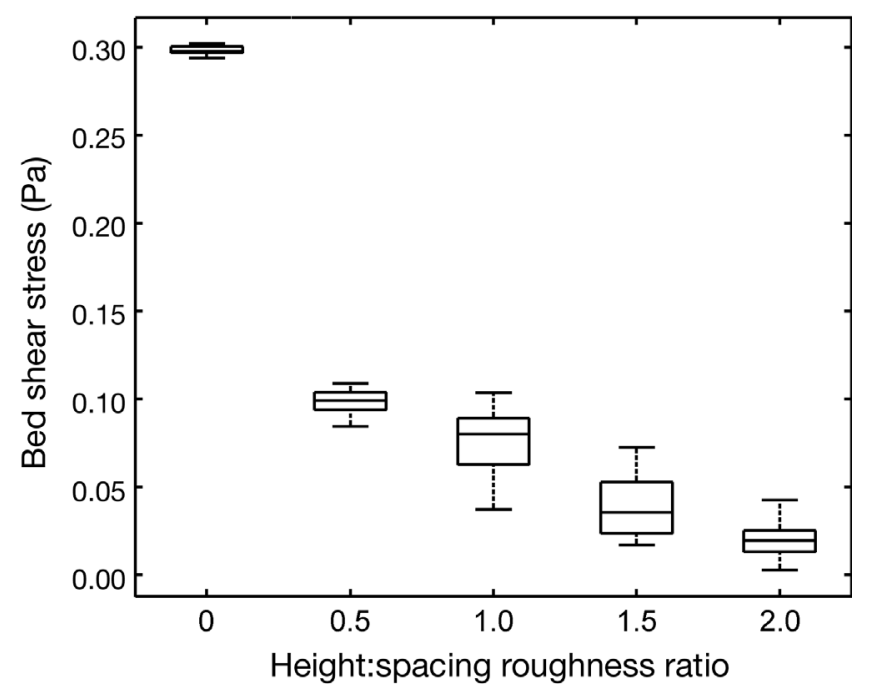

Fig. 10. Bed shear stress along the surfaces of various height: spacing roughness ratio topography. Values shown are for a mean flow of $15 \mathrm{~cm} \mathrm{~s}^{-1}$, while similar trends occurred for all other mean flows tested between 5 and $20 \mathrm{~cm} \mathrm{~s}^{-1}$. A height:spacing ratio $=0$ indicates the surface was flat. Settlement location was along the mid-point of roughness, as shown in Fig. 9. Key to box and whiskers see Fig. 7 legend

\section{DISCUSSION}

The effects of bed roughness on the distribution of mean velocity, turbulence, and bed shear were investigated by quantifying velocity and turbulence profiles over 4 adjacent intertidal sites: a healthy Crassostrea virginica reef composed of tightly packed and vertically oriented live oysters, restoration sites composed of deposited single valve $C$. virginica oyster shell and Busycotypus canaliculatus whelk shell, and a region where the seafloor was primarily composed of silt or clay muds. The $C$. virginica reef generated turbulent stresses that were largest near the tips of the oysters, but were substantially reduced within the reef interstices, regions of low flow and turbulent stresses occurred. In addition to enhanced drag caused by the $C$. virginica reef, the structure of the turbulence also differed compared to the restoration sites. Typically, momentum transport over rough surfaces is dominated by ejection and sweeping events. For flow over the $C$. virginica reef, contributions to the Reynolds stress were particularly dominated by turbulent sweeps (motion in Quadrant Q4), which indicates dominance in turbulent motions that transport high momentum fluid towards the bed. At both restoration sites, there was a roughly equal contribution to ejection and sweep events, with $35 \%$ in Quadrants Q2 and Q4, respectively. At the mud site, ejection events (Q2) were dominant, accounting for $46 \%$ of all turbulent motions.

The transition in dominant direction of momentum transfer from upward ejections to downward sweeps that occurs with enhanced roughness may aid in larval delivery to the bed (Hendriks et al. 2006), where downward sinking rates may be enhanced due to this non-isotropic turbulence, increasing fluid motion towards the bed. In addition, oyster larvae are known to exhibit active substrate choice when transported within ambient flows (Turner et al. 1994, Finelli \& Wethey 2003) and enhanced near-bed turbulence, like that caused by roughness, has been shown to initiate sinking response in larvae (Fuchs et al. 2007). Although turbulence plays an important role in the vertical transport of larvae through the water column, ultimately near-bed turbulence is expected to have a non-linear effect on total settlement, altering 
both the larva's mean time to contact the substratum (McNair 2006) and the probability of successful attachment (Crimaldi et al. 2002).

\section{Larval recruitment to benthic surfaces}

Combined field and lab studies utilizing settlement plates of varying height:spacing ratios suggest that an increase in bed roughness is beneficial for larval recruitment. Narrowly spaced, vertically oriented, roughness elements created interstitial regions sheltered from high velocities and bed shear stresses that have been previously shown to prevent recruitment (Eckman et al. 1990, Koehl \& Hadfield 2010) or cause larval dislodgement after initial contact (Jonsson et al. 2004). Regions of low bed shear stresses within these interstitial regions corresponded closely with highest recruitment density. Both the Crassostrea virginica reef and oyster restoration site had similar vertical relief (elevation with respect to mean water level), but the oyster restoration site lacked substantial roughness and did not have similar recruitment densities compared to the $C$. virginica reef. In addition, the more topographically complex whelk shell site also had higher densities of larval recruitment than the oyster shell restoration site, even though it was at a lower vertical elevation with respect to mean water level.

These results agree well with Mullineaux \& Butman (1991), who found that the strongest correlation between settlement of barnacle larvae and flow was along benthic regions with low turbulence, low shear, and advection away from the surface created by boundary layer separation. They found that enhanced settlement varied inversely with shear stress on all settlement plates with varying geometries, but the correlation with turbulence was mixed and nonsignificant, suggesting shear stress has a greater influence on settlement than local turbulence levels. Our field and laboratory measurements indicate that these regions of low turbulence and shear and advection away from the surface coincide with recirculation zones along the downstream sides of roughness elements, similar to results found by Breitburg et al. (1995), which showed that larger aggregations of larvae were found adjacent to downcurrent sides of roughness elements that created zones of low-flow.

Previous studies have shown that the complex 3dimensional structure created by years of successive settlement on oyster reefs provide physical and biological refugia for oysters (Bartol \& Mann 1997), and even micro-scale variations in elevation and location within the substrate can strongly affect settlement processes. Bartol et al. (1999) showed that intertidal oysters residing within the reef interstices grew faster and had greater survival rates than oysters at the reef surface. Oyster survival and growth were monitored on intertidal reefs constructed from Crassostrea virginica oyster shell and a less structurally complex surf clamshell, Spisula solidissima, within the Chesapeake Bay, USA (Nestlerode et al. 2007). Although similar settlement rates were found at both sites, less mortality and greater growth occurred on the oyster shell reef. Across an elevation gradient on the clamshell reef, larger, more structurally complex shell fragments were scattered around the reef base, with smaller, more tightly packed shell fragments along the crest. Oysters were both larger and more abundant at the reef base, suggesting the availability of interstitial space and appropriate settlement surfaces is the major contributor to the observed differences in oyster abundance at different reef elevations. Our findings showed similar trends of enhanced oyster abundance with greater interstitial surface area, and suggest that these regions reduce bed shear stresses up to 20 fold compared to exposed, horizontally flat surfaces, increasing the likelihood for settlement success of larvae (Jonsson et al. 2004). In addition, although not directly measured, these tightly packed, vertical surfaces may also provide additional refuge from predation (Grabowski 2004). Blue crabs (Callinectes sapidus) are major predators of oysters and can cause high mortality rates in juvenile oyster populations. The vulnerability of an oyster to predation is a function of oyster shell height, shell thickness, and attachment location, but juvenile oysters attached within depressions on the reef are less likely to be preyed upon because of the crabs' limited ability to reach the oyster (Eggleston 1990).

Numerical models (Eckman 1990, Gross et al. 1992), as well as flume studies, (Mullineaux \& Butman 1991) suggest that increased water velocities and turbulence increases the rate of larval transport to the substratum. However, Crimaldi et al. (2002) found that the decrease in anchoring probability caused by high turbulence has a larger effect on overall settlement success than does the increase in larval transport to the substratum. Therefore, flow forces imposed on settling larvae, which cause detachment, should reduce settlement to a greater extent than the increase in larval transport to the benthos from enhanced turbulence and flow. Thus, the ability of Crassostrea virginica larvae to land on sheltered surfaces within the reef should enhance 
their probability of settlement success. The behavior of larvae after they contact a surface can affect where they ultimately settle. How long a larva can explore the surface before attaching to it depends upon the length of interval between pulses of high hydrodynamic stress and how strongly they can adhere to the surfaces (Mullineaux \& Butman 1991, Reidenbach et al. 2009).

Crimaldi et al. (2002) found that increased densities of adult clams would likely decrease the settlement success of larvae due to changes in the structure of the episodic turbulent stresses that occur. However, they noted that they could not extend their conclusions into very dense beds of adult bivalves, because their measurement technique (laser Doppler anemometry) required optical access to the settlement sites. Our field findings suggest that at high adult bivalve densities, such as that are found on the Crassostrea virginica reef, although area averaged fluid shear may be greater, local turbulence and shear stresses within interstices between adults are reduced and can provide adequate refuge for settlement. Adjacent to the bed, instantaneous fluid velocities and Reynolds stresses were substantially reduced, and peak stresses were 10 times lower within interstices between vertically oriented living oysters on the $C$. virginica reef as compared to the oyster restoration site. In addition, the turbulence adjacent to the $C$. virginica reef was isotropic, with $u^{\prime} w^{\prime}=0$ at $z=0.5 \mathrm{~cm}$, while at the restoration site, ejection or sweep motions were still evident, suggesting fluid shear was still being produced.

Although field measurements were conducted primarily during time periods of low wave activity, storms occasionally create wind-waves with heights up to $0.3 \mathrm{~m}$ within the Virginia coastal bays (Hansen \& Reidenbach 2012). Waves have been found to increase hydrodynamic forces on larvae up to 10 times greater than larvae exposed to just unidirectional currents (Reidenbach et al. 2009). This enhancement is due to the relatively small thickness of the wave boundary layer, which can increase velocities and fluid shear adjacent to settlement surfaces. Oscillatory flows were also found to be able to more effectively penetrate into benthic interstices as compared to unidirectional flows (Reidenbach et al. 2009), which may enhance bed shear and probability for larval dislodgement within oyster reefs. In addition to directly quantifying attachment strengths of oyster larvae to benthic surfaces, additional experiments to determine the effects of wave forces on larval recruitment to oyster reefs and restoration sites are still needed.

\section{Sedimentation effects on oyster recruitment}

Oyster reefs form hard substrate within coastal habitats where the sedimentary environment is often composed of fine particulates (Nestlerode et al. 2007). These sediments are subjected to transport as bed load or suspended load, where near-bed turbulent conditions enhance suspension of particles (Papanicolaou et al. 2001). If the sedimentation rate is too great, oyster larvae, as well as juvenile and adult oysters, can be buried, negatively affecting recruitment and growth (MacKenzie 1983). Lenihan (1999) found that sedimentation was seasonally highest at the bases of the reefs, where oysters experienced far greater mortality $(97 \pm 6 \%$; mean $\pm 1 \mathrm{SD})$ than those on the reef crest $(24 \pm 9 \%)$. Macro-predators such as fish and crabs only accounted for $4-20 \%$ of total oyster mortality regardless of reef height, with the greatest effect due to flow-mediated sedimentation dynamics. Our field results showed that along the Crassostrea virginica reef, lower SSC was observed at higher elevations on the reef and reductions in SSC also occurred over the $C$. virginica reef compared to either of the restoration sites. These findings suggest that due to the increased elevation of the $C$. virginica reef, and possibly due to enhanced filtration of sediment-laden water by the benthic community, suspended sediment concentrations were reduced. Locations of higher SSC were correlated with regions of lower recruitment and indicate that the physical structure and location of the habitat can have a major influence on the growth and survival of oyster communities.

The greatest larval recruitment densities on the settlement plates occurred near the peaks in roughness, while lower recruitment was found within the interstitial valleys where shear stresses, lift, and drag forces are lower. However, within the valleys between the triangular-shaped roughness, sediment accumulated, which often covered a great proportion of the total surface area on plates with lower height: spacing roughness ratios. In addition, no recruitment was found on flat settlement plates where sediment completely covered the plate surfaces after 5 mo of deployment. Although, low recruitment on settlement plates cannot be solely attributed to sedimentation, Soniat et al. (2004) looked at statistical differences in recruitment between narrowly spaced vertical shells, widely spaced vertical shells, and horizontally placed shells. When sedimentation was low, greatest recruitment was found on horizontally oriented surfaces. During periods of high sedimentation, recruitment and survival of oysters was highest on vertically oriented substrates that prevent burial by sediments, re- 
gardless of its effectiveness as a refuge from predation. They concluded that although fewer oysters settle on vertically oriented shells, those that do have a higher rate of survival. Our results support these findings by revealing that more vertically oriented structures increase recruitment densities, in part through successful settlement of larvae along regions that are not susceptible to burial by sediments.

\section{Implications for restoration efforts}

The recruitment of larvae to benthic surfaces is an ecologically important process that affects population dynamics and benthic community structure (Nowell \& Jumars 1984, Eckman 1996). Improved restoration of oyster habitat depends upon creating benthic environments that limit sedimentation and predation, but also allow for the successful settlement and recruitment of larvae. Previous studies have emphasized the importance of the elevation of intertidal restoration habitats with respect to mean water level (Schulte et al. 2009) to improve oyster growth and survival, which alters water flow and reduces sedimentation (Bartol \& Mann 1997, Lenihan 1999). Our results suggest that the availability of interstitial space, combined with vertically oriented roughness elements that limit bed stresses and prevent sediment accumulation, can also enhance oyster abundances. Roughness elements created artificially, or through the use of larger shells than those that typically constitute restoration sites, can provide levels of surface and interstitial heterogeneity that create physical and biological refugia for oysters that are critical to the early development of oyster reef communities.

Acknowledgements. We gratefully acknowledge B. Truitt, B. Lusk, and The Nature Conservancy for access to oyster restoration sites, logistical support, and assistance with measurements of oyster recruitment densities. J. Selph, A. Schwarzschild, C. Buck, and D. Boyd provided field assistance. This research was funded by a Virginia Coast Reserve Long Term Ecological Research grant by the National Science Foundation (NSF-DEB 0621014).

\section{LITERATURE CITED}

Antonia RA, Luxton RE (1971) The response of a turbulent boundary layer to a step change in surface roughness: Part 1. Smooth to rough. J Fluid Mech 48:721-761

Bartol IK, Mann R (1997) Small-scale settlment patterns of the oyster Crassostrea virginica on a constructed intertidal reef. Bull Mar Sci 61:881-897

Bartol IK, Mann R, Luckenbach ML (1999) Growth and mortality of oysters (Crassostrea virginica) on constructed intertidal reefs: effects of tidal height and substrate level.
J Exp Mar Biol Ecol 237:157-184

Bennet SJ, Best JL (1996) Mean flow and turbulence structure over fixed ripples and the ripple-dune transition. In: Ashworth PJ, Bennet SJ, Best JL, McLelland SJ (eds) Coherent flow structures in open channels. John Wiley, New York, NY, p 281-304

Breitburg DL, Palmer MA, Loher T (1995) Larval distributions and the spatial patterns of settlement of an oyster reef fish: responses to flow and structure. Mar Ecol Prog Ser 125:45-60

Breitburg DL, Coen LD, Luckenbach MW, Mann R, Posey M, Wesson JA (2000) Oyster reef restoration: convergence of harvest and conservation strategies. J Shellfish Res 19:371-377

> Bushek D (1988) Settlement as a major determinant of intertidal oyster and barnacle distributions along a horizontal gradient. J Exp Mar Biol Ecol 122:1-18

Butman CA (1987) Larval settlement of soft-sediment invertebrates: the spatial scales of pattern explained by active habitat selection and the emerging role of hydrodynamical processes. Oceanogr Mar Biol Annu Rev 25:113-165

Butman CA, Frechette M, Geyer WR, Starczak VR (1994) Flume experiments on food supply to the blue mussel Mytilus edulis L. as a function of boundary-layer flow. Limnol Oceanogr 39:1755-1768

Cerco CF, Noel MR (2007) Can oyster restoration reverse cultural eutrophication in Chesapeake Bay? Estuaries Coasts 30:331-343

Cheng RT, Ling CH, Gartner JW (1999) Estimates of bottom roughness length and bottom shear stress in South San Francisco Bay, California. J Geophys Res 104:7715-7728

> Coen LD, Luckenbach MW (2000) Developing success criteria and goals for evaluating oyster reef restoration: ecological function or resource exploitation? Ecol Eng 15:323-343

> Cowen EA, Monismith SG (1997) A hybrid digital particle tracking velocimetry technique. Exp Fluids 22:199-211

> Crimaldi JP, Thompson JK, Rosman JH, Lowe RJ, Koseff JR (2002) Hydrodynamics of larval settlement: the influence of turbulent stress events at potential recruitment sites. Limnol Oceanogr 47:1137-1151

> Dame RF, Zingmark RG, Haskin E (1984) Oyster reefs as processors of estuarine materials. J Exp Mar Biol Ecol 83: 239-247

Eckman JE (1990) A model of passive settlement by planktonic larvae onto bottoms of differing roughness. Limnol Oceanogr 35:887-901

Eckman JE (1996) Closing the larval loop: linking larval ecology to the population dynamics of marine benthic invertebrates. J Exp Mar Biol Ecol 200:207-237

> Eckman JE, Savidge WB, Gross TF (1990) Relationship between duration of cyprid attachment and drag forces associated with detachment of Balanus amphitrite cyprids. Mar Biol 107:111-118

Eggleston DB (1990) Foraging behavior of the blue crab, Callinectes sapidus, on juvenile oysters, Crassostrea virginica: effects of prey density and size. Bull Mar Sci 46:62-82

Finelli CM, Wethey DS (2003) Behavior of oyster (Crassostrea virginica) larvae in flume boundary layer flows. Mar Biol 143:703-711

Fredriksson DW, Steppe CN, Wallendorf L, Sweeney S, Kriebel D (2010) Biological and hydrodynamic design considerations for vertically oriented oyster grow out structures. Aquacult Eng 42:57-69

Fuchs HL, Neubert MG, Mullineaux LS (2007) Effects of turbulence-mediated larval behavior on larval supply and 
settlement in tidal currents. Limnol Oceanogr 52: 1156-1165

- Grabowski JH (2004) Habitat complexity disrupts predatorprey interactions but not the trophic cascade on oyster reefs. Ecology 85:995-1004

Grass A (1971) Structural features of turbulent flow over smooth and rough boundaries. J Fluid Mech 50:233-255

> Gross TF, Nowell AR (1983) Mean flow and turbulence scaling in a tidal boundary layer. Cont Shelf Res 2:109-126

$>$ Gross TF, Werner FE, Eckman JE (1992) Numerical modeling of larval settlement in turbulent bottom boundary layers. J Mar Res 50:611-642

- Hansen JCR, Reidenbach MA (2012) Wave and tidally driven flows in eelgrass beds and their effect on sediment suspension. Mar Ecol Prog Ser 448:271-287

> Hendriks IE, Van Duren LA, Herman PMJ (2006) Turbulence levels in a flume compared to the field: implications for larval settlement studies. J Sea Res 55:15-29

> Jonsson PR, Berntsson KM, Larsson AI (2004) Linking larval supply to recruitment: flow-mediated control of initial adhesion of barnacle larvae. Ecology 85:2850-2859

Kemp WM, Boynton WR, Adolf JE, Boesch DF and others (2005) Eutrophication of Chesapeake Bay: historical trends and ecological interactions. Mar Ecol Prog Ser 303:1-29

Kennedy V, Krantz L (1982) Comparative gametogenic and spawning patterns of the oyster Crassostrea virginica (Gmelin) in central Chesapeake Bay. J Shellfish Res 2: 133-140

Kingsley-Smith PR, Harwell HD, Kellogg ML, Allen SM and others (2009) Survival and growth of triploid Crassostrea virginica (Gmelin, 1791) and C. ariakensis (Fujita, 1913) in bottom environments of Chesapeake Bay: implications for an introduction. J Shellfish Res 28:169-184

Koehl MAR, Hadfield M (2010) Hydrodynamics of larval settlement from a larva's point of view. Integr Comp Biol 50: $539-551$

Lacey RWJ, Roy AG (2008) Fine-scale characterization of the turbulent shear layer of an instram pebble cluster. J Hydraul Eng 134:925-936

Lenihan HS (1999) Physical-biological coupling on oyster reefs: how habitat structure influences individual performance. Ecol Monogr 69:251-275

> Lenihan HS, Peterson CH (1998) How habitat degradation through fishery disturbance enhances impacts of hypoxia on oyster reefs. Ecol Appl 8:128-140

> Loosanoff VL (1965) Gonad development and discharge of spawn in oysters of long island sound. Biol Bull 129: $546-561$

Lu SS, Willmarth WW (1973) Measurements of the structure of the Reynolds stress in a turbulent boundary layer. J Fluid Mech 60:481-571

> Lueck RG, Lu Y (1997) The logarithmic layer in a tidal channel. Cont Shelf Res 17:1785-1801

MacKenzie C (1983) To increase oyster production in the Northeastern United States. Mar Fish Rev 45:1-22

McCormick-Ray M (1998) Oyster reefs in 1878 seascape pattern-Winslow revisited. Estuaries Coasts 21:784-800

McNair JN (2006) Probabilistic settling in the Local Exchange Model of turbulent particle transport. J Theor Biol 241:420-437

> Mullineaux LS, Butman CA (1990) Recruitment of benthic invertebrates in boundary-layer flows: a deep water experiment on Cross Seamount. Limnol Oceanogr 35:409-423

Mullineaux LS, Butman CA (1991) Initial contact, exploration and attachment of barnacle (Balanus amphitrite) cyprids settling in flow. Mar Biol 110:93-103

> Mullineaux LS, Garland ED (1993) Larval recruitment in response to manipulated field flows. Mar Biol 116:667-683

Nelson KA, Leonard LA, Posey MH, Alphin TD, Mallin MA (2004) Using transplanted oyster (Crassostrea virginica) beds to improve water quality in small tidal creeks: a pilot study. J Exp Mar Biol Ecol 298:347-368

> Nestlerode JA, Luckenbach ML, O'Beirn FX (2007) Settlement and survival of the oyster Crassostrea virginica on created oyster reef habitats in Chesapeake Bay. Restor Ecol 15:273-283

Newell RIE (1988) Ecological changes in Chesapeake Bay: are they the result of over harvesting the American oyster, Crassostrea virginica. In: Understanding the estuary: advances in Chesapeake Bay research. Chesapeake Research Consortium Publications 129, Baltimore, MD, p 536-546

> Nowell ARM, Jumars PA (1984) Flow environments of aquatic benthos. Annu Rev Ecol Syst 15:303-328

Nowell ARM, Jumars PA (1987) Flumes: theoretical and experimental considerations for simulation of benthic environments. Oceanogr Mar Biol Annu Rev 25:91-112

- Papanicolaou AN, Diplas P, Dancey CL, Balakrishnan M (2001) Surface roughness effects in near-bed turbulence: implications to sediment entrainment. J Eng Mech 127: 211-218

> Reidenbach MA, Monismith SG, Koseff JR, Yahel G, Genin A (2006) Boundary layer turbulence and flow structure over a fringing coral reef. Limnol Oceanogr 51:1956-1968

Reidenbach MA, George NT, Koehl MAR (2008) Antennule morphology and flicking kinematics facilitate odor sampling by the spiny lobster, Panulirus argus. J Exp Biol 211:2849-2858

Reidenbach MA, Koseff JR, Koehl MAR (2009) Hydrodynamic forces on larvae affect their settlement on coral reefs in turbulent, wave-driven flow. Limnol Oceanogr 54:318-330

Rothschild BJ, Ault JS, Goulletquer P, Heral M (1994) Decline of the Chesapeake Bay oyster population: a century of habitat destruction and overfishing. Mar Ecol Prog Ser 111:29-39

Schlichting H, Gersten K (2000) Boundary layer theory, 8th edn. Springer, New York, NY

Schulte DM, Burke RP, Lipcius RN (2009) Unprecedented restoration of a native oyster metapopulation. Science 325:1124-1128

Soniat TM, Finelli CM, Ruiz JT (2004) Vertical structure and predator refuge mediate oyster reef development and community dynamics. J Exp Mar Biol Ecol 310:163-182

Tamburri MN, Finelli CH, Wethey DS, Zimmer-Faust RK (1996) Chemical induction of larval settlement behavior in flow. Biol Bull 191:367-373

Thompson RJ, Newell RIE, Kennedy VS, Mann R (1996) Reproduction and larval development. In: Kennedy VS, Newell RIE, Eble AF (ed) The Eastern Oyster, Crassostrea virginica. Maryland Sea Grant Publication, College Park, MD, p 335-370

Turner EJ, Zimmer-Faust RK, Palmer MA, Luckenbach ML, Pentcheff ND (1994) Settlement of oyster (Crassostrea virginica) larvae: effects of water flow and water-soluble chemical cue. Limnol Oceanogr 39:1579-1593

Wethey DS (1986) Ranking of settlement cues by barnacle larvae: influence of surface contour. Bull Mar Sci 39:393-400

Zimmer-Faust RK, Tamburri MN (1994) Chemical identity and ecological implications of a waterborne, larval settlement cue. Limnol Oceanogr 39:1079-1083 